\title{
The pursuit of perfection should not impede the struggle for improvement
}

\author{
Joseph S. Coselli, MD
}

\footnotetext{
From the Division of Cardiothoracic Surgery, Michael E. DeBakey Department of Surgery, Baylor College of Medicine; Department of Cardiovascular Surgery, Texas Heart Institute; and CHI St Luke's Health-Baylor St Luke's Medical Center, Houston, Tex.

This editorial was not funded.

Disclosures: Author has nothing to disclose with regard to commercial support.

Received for publication July 10, 2018; accepted for publication July 13, 2018; available ahead of print Aug 21, 2018.

Address for reprints: Joseph S. Coselli, MD, Division of Cardiothoracic Surgery, Michael E. DeBakey Department of Surgery, Baylor College of Medicine, One Baylor Plaza, BCM 390, Houston, TX 77030 (E-mail: jcoselli@bcm.edu).

J Thorac Cardiovasc Surg 2019;157:199-200

$0022-5223 / \$ 36.00$

Copyright (C) 2018 by The American Association for Thoracic Surgery

https://doi.org/10.1016/j.jtcvs.2018.07.032
}

Despite decades of extensive effort, patients, particularly young patients faced with aortic valvular pathology necessitating replacement, encounter the stark reality that there is no perfect substitute for the aortic valve. The fact remains that bioprosthetic and mechanical aortic valves are subject to high rates of valve-related complications. ${ }^{1}$ Notably, patients with bioprosthetic valves face questions related to long-term durability, whereas those with mechanical valves are constrained by the need for lifelong anticoagulation. Since its initial description by the late Donald Ross, ${ }^{2}$ the Ross procedure, which uses a pulmonary autograft to replace the aortic valve and a homograft to replace the pulmonary valve, has met with intermittent and varying levels of enthusiasm. The Ross procedure is undoubtedly more complex and technically challenging to perform (with procedure-specific inherent risks as well as those stemming from longer cardiac ischemic times) than a typical mechanical aortic valve replacement. Further, the potential benefits of performing the Ross procedure in young patients are often overshadowed by concern regarding the development of late aortic root dilatation and related aortic valvular insufficiency. During recent decades, the use of bioprosthetic heart valves has steadily increased, both in general use and specifically for patients between the ages of 18 and 50 years. ${ }^{3,4}$ The reasons for this trend are multifactorial, but they stem more from quality of life interests in patients seeking to avoid long-term anticoagulation regimens than from improved durability of bioprosthetic valves.

David and colleagues ${ }^{5}$ describe, in an elegantly analyzed article in this issue of the Journal, their experience with the Ross procedure in a consecutive series of 212 patients with long-term follow-up out to 25 years. Their results are extraordinary; they report a cumulative mortality at 20 years of $10.8 \%$, and Ross-related reoperation was needed by only 30 patients. Representing extraordinary surgical skill and judgment, Ross-related reoperation encompassed a

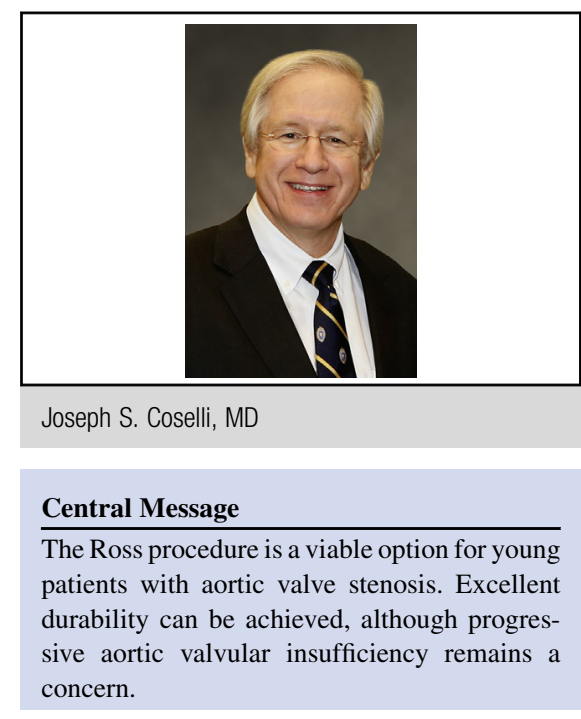

See Article page 201.

cumulative probability of $16.8 \%$ at 20 years, which was $11.5 \%$ for pulmonary autograft reoperation and $8.2 \%$ for pulmonary homograft reoperation. Even though the longterm rate of development of aortic insufficiency and the related rate of reoperation were low, David and colleagues 5 did note that aortic insufficiency increased steadily through the course of follow-up. After analysis, however, David and colleagues ${ }^{5}$ could not establish an association between the valve lesion, the technique of implantation, any dilatation of the aorta and subsequent development of significant aortic valvular insufficiency, and the need for reoperation for such.

David and colleagues ${ }^{5}$ conclusively add to the current surgical literature and establish that for patients with aortic valve stenosis, particularly those of a younger age seeking to avoid a long-term anticoagulation regimen, the Ross procedure should be included as a viable option. One caveat would be that optimal results for the Ross procedure would, as a consequence of its procedural complexity, naturally be obtained by surgeons with expert skill and substantial experience located in high-volume centers. In addition to establishing clearer contraindications to performing the Ross procedure, such as patients with heritable thoracic aortic disease (eg, Marfan syndrome), David and colleagues ${ }^{5}$ suggest that repair in patients with a dilated annulus and aortic valvular insufficiency, particularly in those with bicuspid aortic valves, must be approached with caution and with 
an increased awareness of possible premature failure of the pulmonary autograft. Although perfection in the form of an aortic valve substitute remains elusive for young adults with aortic valvular stenosis, the Ross procedure may present an underutilized opportunity for improved longevity and enhanced quality of life.

\section{References}

1. Zhao DF, Seco M, Wu JJ, Edelman JB, Wilson MK, Vallely MP, et al. Mechanical versus bioprosthetic aortic valve replacement in middle-aged adults: a systematic review and meta-analysis. Ann Thorac Surg. 2016;102:315-27.
2. Ross DN. Replacement of aortic and mitral valves with a pulmonary autograft. Lancet. 1967;2:956-8.

3. Schnittman SR, Adams DH, Itagaki S, Toyoda N, Egorova NN, Chikwe J Bioprosthetic aortic valve replacement: revisiting prosthesis choice in patients younger than 50 years old. J Thorac Cardiovasc Surg. 2018;155: 539-47.e9.

4. Isaacs AJ, Shuhaiber J, Salemi A, Isom OW, Sedrakyan A. National trends in utilization and in-hospital outcomes of mechanical versus bioprosthetic aortic valve replacements. J Thorac Cardiovasc Surg. 2015; 149:1262-9.e3.

5. David TE, Ouzounian M, David CM, Lafreniere-Roula M, Manlhiot C. Late results of the Ross procedure. J Thorac Cardiovasc Surg. 2019;157: 201-8. 